\title{
Pornô Cultural: da concepção pornográfica como Indústria Cultural ao movimento Feminista Pornô
}

\author{
Porno Cultural: de la concepción pornográfica como Industria Cultural \\ al movimiento Feminista Porno
}

\section{Porn Cultural: from pornographic conception like Cultural Industry to the Feminist Porn movement}

\author{
Flávia Lages de Castro' \\ Juliana Crespo"
}

\footnotetext{
Palavras chave:

Pornografia

Indústria Cultural

Mainstream

Pornô-feminista

Contra-hegemonia
}

\section{Resumo:}

Este artigo pretende discutir a sexualidade como campo e suas disputas, abordando a categoria pornografia para entendimento de sua configuração como fenômeno social. Perpassando pela construção epistêmica de seu termo ao longo dos séculos através do olhar da sociedade Ocidental. Além disso, pretende destrinchar, principalmente, suas especificidades ao decorrer das décadas do século $X X$, quando se atrela à Indústria Cultural e seus desvios, sobretudo, com a pulsão do movimento feminista pornô nas artes na primeira década do século $X X I$, que de certa forma redimensionam o caráter comercial da pornografia e atuam como manifestação política de empoderamento e emancipação da mulher. 


\section{Resumen:}

Este artículo pretende discutir la sexualidad como campo y sus disputas, a la categoría de pornografía para comprender su configuración como un fenómeno social. Evitando la construcción epistémica de su término largo de los siglos a través de los ojos de la sociedad occidental. Además, quiere molestar, principalmente, sus características específicas en el curso de las décadas del siglo XX, cuando se conecta a la industria Cultural y sus desviaciones estándar, en particular, con el impulso del movimiento feminista pornográfico en la primera década del siglo XXI, que de alguna manera cambiar el carácter comercial de la pornografía y actuar como manifestación política de la potenciación y emancipación de la mujer.
Palabras clave:

Cultura popular

Políticas Culturales

Edictos

Profesionalización artística

Bongar

\section{Keywords:}

Pornography

Cultural Industry

Mainstream

Porn-feminist

Counter-hegemony

\section{Abstract:}

This article intends to discuss sexuality as a dispute field, approaching the category pornography to understand its as a social phenomenon. Going through the epistemic construction of its term through the centuries through the eyes of Western society. In addition, it seeks to unravel, mainly, its specificities during the decades of the twentieth century, when it is tied to the Cultural Industry and its deviations, mainly, with the drive of the feminist pornographic movement in the arts in the first decade of the 21st century, that in a certain way reshape the commercial character of pornography and act as a political manifestation of women's empowerment and emancipation. 


\section{Pornô Cultural: da concepção pornográfica como Indústria Cultural ao movimento Feminista Pornô}

\section{O campo da Sexualidade e suas disputas}

O conceito de campo atribui uma perspectiva de pensamento relacional, desta forma o objeto ou fenômeno é concebido em constante relação e movimento. O campo também pressupõe confronto, tomada de posição, luta, tensão, poder, já que, de acordo com Bourdieu, todo campo "é um campo de forças e um campo de lutas para conservar ou transformar esse campo de forças" (BOURDIEU, 2004, p. 22-23).

Os campos são formados por agentes, indivíduos e instituições, que criam espaços 'microcosmos' dotados de certa autonomia, ao mesmo tempo em que submetidos ao 'macrocosmo', ou seja, as leis sociais mais amplas. Para o sociólogo francês os 'microcosmos' jamais escapam das imposições do macrocosmo, cada campo dispõe com relação a este, de uma autonomia parcial mais ou menos acentuada.

As relações estabelecidas nesses espaços possuem diferentes possibilidades de tomada de estrutura dependendo a posição ocupada por estes agentes. Pois, é no interior dos campos que existem disputas por controle e legitimação dos bens produzidos, assim como também são estabelecidas diferentes relações e assumidas variadas posturas pelos agentes que os compõem.

O grau de autonomia de um campo aumenta à medida que este é mais bem estruturado, e para analisá-lo é preciso:
[...] saber qual é a natureza das pressões externas, a forma sob a qual elas se exercem, créditos, ordens, instruções, contratos, e sob quais formas se manifestam as resistências que caracterizam a autonomia, isto é, quais são os mecanismos que o microcosmo aciona para se libertar dessas imposições externas e ter condições de reconhecer apenas suas próprias determinações internas. (BOURDIEU, 2004, p. 21).

A resistência aos fatores externos de determinado campo depende do seu grau de autonomia, que autor denomina de capacidade ou poder de "refração", que significa a possibilidade de transfigurar as imposições externas ao ponto de "se tornarem perfeitamente irreconhecíveis" (BOURDIEU, 2004, p. 23). Porém, o campo também pode ser 'heterônomo', quando as pressões e os problemas externos exercidos sobre ele são bastante influentes para sua própria configuração.

Em relação à disputa entre os agentes pertencente a determinado campo estão estreitamente relacionadas à posição que estes ocupam que são nomeadas, de acordo com Bourdieu (1983), de 'pretendentes', os novos que estão entrando no campo buscam sua posição, ou 'dominantes', aqueles já estabelecidos e que lutam para manter-se na posição alcançada.

[...] em cada campo se encontrará uma luta, da qual se deve, cada vez, procurar as formas específicas, entre o novo que está entrando e que tenta forçar o direito de entrada e o dominante que tenta defender o monopólio e excluir a concorrência. (BOURDIEU, 1983, p.89)

As atitudes dentro de determinado campo são estabelecidas de variadas maneiras, segundo Bourdieu, podendo ser aceita as normas, pela boa vontade 
em relação à cultura e às regras legitimadas, e outra denominada "herética", ou seja, contestação das regras e posições, porém é possível atitudes híbridas em ambas as posturas.

Ao abordar a sexualidade como campo, para que seja possível o entendimento de sua construção como fator sócio cultural, é possível perceber que seu 'microscosmo' receberam inúmeras influências de outros fatores macros, como ordenamento jurídico e religioso, e de outros campos, como da biologia, da medicina e da psicanálise, de forma bastante distinta ao longo de determinados tempo-espaço. Neste sentido o campo da sexualidade se configura como um 'heterônomo', onde diversos agentes constroem suas formas legitimadoras muitas vezes baseados em preceitos distintos ao seu próprio campo de interesse.

Heilborn (1999) apresenta que a sexualidade deve ser percebida como esfera social, pois suas formas de abordagens, enunciações e práticas extrapolam o entendimento das diferenças individuais e perpassam diferentes roteiros sociais.

Mais do que um recurso explicativo baseado em diferenças psicológicas, essa variação é efeito de processos sociais que se originam no valor que a sexualidade ocupa em determinados nichos sociais e nos roteiros específicos de socialização com que as pessoas se deparam. (HEILBORN, 1999, p.40).

Entende-se sexo como a denominação do aparato biológico, anatômico, que se diferencia entre homens e mulheres, além das práticas e comportamentos vinculados à relação sexual, resultantes das concepções existentes a respeito. Tais diferenças são organizadas desde a concepção, porém os signos associados a este são construídos histórico-socialmente, principalmente, no que concerne a sexualidade; a qual se compõe de acordo com as relações e identidades socialmente construídas e historicamente modeladas (MAIO, 2008, p.18).

Anthony Giddens (1993) diz que a sexualidade é uma temática que por ser essencialmente privada, poderia ser de irrelevância pública e também um fator permanente, por se tratar de um componente biológico, e como tal necessária à continuidade das espécies. Entretanto, observa também que as questões sexuais aparecem continuamente no domínio público, especialmente na atualidade, cuja sexualidade está cada vez mais atrelada a descobertas que propiciam o desenvolvimento de estilos de vida bastante variados.

Devido aos aspectos sociais, a sexualidade extrapola a preocupação individual e se torna uma questão crítica e política, tornando-se algo a ser investigado por uma análise minuciosa das rupturas históricas e dos aspectos sociológicos, que envolve "rituais, fantasias, representações, símbolos, convenções... Processos profundamente culturais e plurais" (LOURO, 2001, p.11).

É algo que cada um "tem", ou cultiva, não mais uma condição natural que um indivíduo aceita como um estado de coisas preestabelecido. De algum modo, que tem de ser investigado, a sexualidade funciona como um aspecto maleável do eu, um ponto de conexão primário entre o corpo, a auto-identidade e as normas sociais (GIDDENS, 1993, p.25).

A crise pela busca por sentido e formas de representação sobre gênero, sexo e sexualidade emerge dentro do contexto cultural atual, segundo Jefrey Weeks, devido às significações e a im- 
portância que atribuímos esses aspectos em "(...) nossas vidas e em nossos relacionamentos, sobre a identidade e o prazer, a obrigação e a responsabilidade, e sobre a liberdade de escolha" (WEEKS, 2001, p. 74).

\begin{abstract}
Nossas definições, convenções, crenças, identidade e comportamentos sexuais não são o resultado de uma simples evolução, como se tivessem sido causados por algum fenômeno natural: eles têm sido modelados no interior de relações definidas de poder. A mais óbvia dessas relações já foi assinalada na citação de Krafft-Ebing: as relações entre homens e mulheres, nas quais a sexualidade feminina tem sido historicamente definida em relação à masculina (WEEKS, 2001, p.48).
\end{abstract}

Desta forma, de acordo com Maio, os escritos sobre sexualidade, tanto a pronúncia quanto a dicção são masculinas, formados por pessoas de classe média, branca e basicamente heterossexuais, seriam estes os agentes 'dominantes' do campo que de forma contundente manteve regras rígidas sobre a sexualidade, como a heteronormatividade, a monogamia e a moralidade familiar, excluindo as concorrências, sobretudo a feminina. Como Maio descreve essas regras morais que atribuem formas vexatórias contém "verdades" incrustadas que estabelecem modelos da expressão e da manifestação sexual até hoje vigentes.

Uma das "verdades" sobre a sexualidade e a vergonha da nudez dos corpos vem do entendimento sobre o que traz a Bíblia [...]. Por conta desse "descobrimento" dos corpos feito na vergonha, após um pecado (o chamado Pecado Original), podemos inferir que a expressão sexual humana não poderia ter vindo me- nos carregada de tabus, mitos, preconceitos, contradições, que foram e vão ainda moldando as atitudes e o comportamento sexual das pessoas (MAIO, 2008, p.25).

Com a perda do sentido religioso, na sociedade moderna, de forma mais consistente e visível, a cultura passa ser a moeda de troca para os processos idealizadores, segundo Terry Eagleton (2011). Ela tem o papel de oferecer "culto, simbolismo, unidade social, identidade coletiva, uma combinação sensível de moralidade e prática espiritual", ou seja, passa a estabelecer esses critérios homogeinizadores de forma sistêmica. Eagleton aponta que o capitalismo industrial, atrelado as suas tendências racionalizadoras e secularizantes, tem a necessidade de legitimar a si mesmo, e utiliza-se da cultura como forma "alternativa lamentável" para religião em dois aspectos:

Em seu sentido artístico mais restrito, ela é limitada a uma percentagem insignificante da população, e em seu sentido social mais amplo, é exatamente o ponto em que homens e mulheres menos estão em harmonia. Cultura, neste último sentido de religião, nacionalidade, sexualidade, etnicidade etc., é um campo de bataIha feroz; de modo que, quanto mais prática se torna a cultura, menos é capaz de cumprir um papel conciliatório, e quanto mais conciliatória ela é, mais ineficaz se torna (EAGLETON, 2011, p.64).

Ao se evidenciar esses fenômenos de natureza moral e social Marilena Chauí diz que as práticas de controle social, proibitivas e permissionárias em relação ao sexo são bastante antigas, destacando que o estudo do seu sentido, as causas e efeitos são bastante recentes; tendo como marco à inserção de forma tardia da palavra sexualidade no dicio- 
nário, devido a ampliação do sentido do termo sexo, que passa a se distinguir e diferenciar entre necessidade (física, biológica), prazer, (físico, psíquico) e desejo (imaginação, simbolização)" (CHAUÍ, 1984 , p. 11). Se torna bastante perceptível a falta de capacidade e poder de 'refração' do campo da sexualidade, devido as inúmeras imposições externas, o que dificulta e muito uma separação deste campo dos demais fatores sociais.

Em consonância com o pensamento da autora supracitada, Maria Luiza Heilborn aponta que a cultura é responsável pela "transformação dos corpos em entidades sexuadas e socializadas, por intermédio de redes de significados que abarcam categorizações de gênero, de orientação sexual, de escolha de parceiros" (HEILBORN, 1999, p. 40). Desta forma, Weeks (2001) observa que os significados que damos à sexualidade e ao corpo por serem socialmente organizados, se modificam ao longo da história, de acordo com o tempo e cada sociedade.

Mesmo compreendendo que se trata de outra matriz de pensamento distinta de Bourdieu, vale ressaltar o estudo feito por Michel Foucault (1926-1984) sobre a "história da sexualidade", pois tem sido central para as discussões sobre o corpo e a sexualidade, partindo da seguinte visão: "Não se deve concebê-la como uma espécie de dado da natureza que o poder tenta pôr em xeque, ou como um domínio obscuro que o saber tentaria, pouco a pouco, desvelar. A sexualidade é o nome que se pode dar a um dispositivo histórico" (Foucault, 1993, p. 100).

Foucault (2008) refere-se ao fato de que até o século XVII ainda vigorava uma franqueza sexual, pois as práticas sexuais não eram escondidas em segredos; eram até estimuladas. O filósofo destaca, o que ele configura como hipótese repressiva, posturas evidenciadas a partir do século XVII, que reduz o sexo a procriação, permitindo somente uma única manifestação possível: a sexualidade do casal monogâmico, legítimo e procriador. Encerrando de forma cuidadosa a própria sexualidade, sendo confiscada pela família conjugal e manifestada dentro de casa, com a função, inteiramente, de reprodução.

O casal, legítimo e procriador, dita a lei. Impõe-se como modelo, faz reinar a norma, detém a verdade, guarda o direito de falar, reservando-se o princípio do segredo.(...) Ao que sobra só resta encobrir-se; o decoro das atitudes esconde os corpos, a decência das palavras limpa os discursos. E se o estéril insiste, e se mostra demasiadamente, vira anormal: receberá este status e deverá pagar as sanções (FOUCAULT, 1980, p. 9-10).

Foucault evidencia que em muitos momentos houve repressão, mas propõe uma análise mais minuciosa da relação entre poder e sexualidade. $\mathrm{O}$ autor aponta que a dinâmica a partir do século XIX, com a inserção do discurso "médico-legal”, fatores entendidos por Bourdieu como "macrocosmos" pertencente respectivamente ao campo da medicina e ao campo jurídico, tem a capacidade de formular regramentos sociais; o que torna esse processo de dominação algo mais sutil (FOUCAULT, 1980, p. 30). Provoca ainda efeitos diversos como: a vigilância, a normatização e a constituição da sexualidade a partir do controle dos corpos das pessoas, por meio da produção e da inscrição da sexualidade, e não pela sua negação e proibição.

O excesso do controle normativo que gera excitação coletiva de curiosidade, unido a uma não proibição, segundo Leite Junior, foi um dos fatores responsáveis pelo surgimento da categoria pornografia no campo da sexualidade, no final 
do século XIX, que tinha como principal objetivo visar à excitação sexual de seu público como única motivação e fim em si mesma. Entretanto, foi somente na segunda metade do século $X X$, especificamente na década de 1970, que a sexualidade e a pornografia passaram a ser constante pauta na vida social, tendo em vista que em diversos países, sobretudo, nos Estados Unidos obteve-se uma legislação mais permissiva, que permitiu a ascensão de inúmeros filmes, teatros adultos e sex shops.

Nestas novas mercadorias, o sexo perde sua intenção de transgressão contra as estruturas sociais vigentes e torna-se expressão da uniformização dos desejos e padronização dos prazeres (...) agora a pornografia não é mais transgressiva e questionadora, pois agora ela quer se afirmar nas atuais bases econômicas e sociais (LEITE JR., 2006, p. 64).

Nesse sentido é possível entender a categoria pornografia como uma possibilidade de 'refração' do campo da sexualidade, para uma configuração mais autônoma de suas regras. Porém, pela necessidade de sua própria visibilidade e inserção como mercadoria massiva, nota-se que os macrocosmos continuam sendo predominantes, se tratando de um campo ainda 'heterônomo'.

Surge assim uma indústria com objetivo de ampliar o público consumidor e gerar lucros, fazendo com que a pornografia de certa forma perca a intenção de transgressão da ordem estabelecida. Pois, epistemologicamente, a palavra "pornografia" se origina do termo grego pornographos, ou seja, escrita sobre prostitutas. Na sua concepção original, o termo se refere aos costumes, à descrição da vida e dos hábitos das prostitutas e de sua relação com os clientes (MORAES; LAPEIZ, 1984, p. 109).
Porém, para ser atribuída a legalidade deste gênero como indústria, os elementos deste material pornográfico eram conduzidos por padrões sexuais aceitos na contemporaneidade, tendo em vista que estes estão relacionados ao sistema de gênero dominante, que Leite Júnior chamará de "gozo legítimo", ou seja, a pornografia legal comercial mainstream, que corresponde a imagens de casais heterossexuais, mas também de gays e travestis todos dentro dos padrões de beleza aceitos pela sociedade (DIAZ-BENITEZ, 2009). Leite destaca também que "mais do que liberar a fruição dos prazeres, a pornografia legaliza da explicita uma padronização dos desejos e uma domesticação dos corpos talvez nunca encontrados antes" (LEITE JR, 2006, p.15).

De acordo com Preciado (2008) a pornografia é um dispositivo virtual, tendo como principal objetivo a prática masturbatória, ou seja, a capacidade de estimulação que o sistema produz independentemente da vontade própria e dos mecanismos responsáveis pela produção do próprio prazer, concluindo que a "representação da sexualidade aspira a controlar a resposta sexual do observador" (PRECIADO, 2010, p. 141). Esses novos mecanismos de imagem que impulsionaram a indústria pornô, desde o século $X X$ demarcam, segundo Preciado (2010) e Leite Júnior (2006), a própria composição do sujeito sexuado, apresentando-se por um processo público e virtual, por isso, segundo os autores, não há como pensar sexualidade na contemporaneidade ocidental sem levar em conta as mudanças tecnológicas.

Victa de Carvalho (2006) atenta que os dispositivos eletrônicos e as experiências proporcionadas pelas Novas Mídias tornam-se um desafio para os mecanismos perceptivos e "indicam a necessidade de uma análise que privilegie o caráter processual da experiência 
que se dá na inter-relação entre sujeito e dispositivo" (CARVALHO, 2006, p. 77). Ao citar Félix Guattari, a autora supracitada, identifica que esses "dispositivos de imersão" provocam alterações na concepção de subjetividade que de certa forma extrapola a "oposição clássica entre sujeito e sociedade" (GUATTARI apud CARVALHO, 2006, p. 78). Desta forma, esses dispositivos se tornam não somente um equipamento técnico, mas sim um "regime de fazer ver e fazer falar" (FOUCAULT apud CARVALHO, 2006, p. 79).

Essa necessidade de visibilidade resulta, na década de 1990, o que Annie Sprinkle chamará de pós-pornô, se intitulando precursora do movimento, atribuindo o mesmo nome em seu próprio livro "Post-Porn Modernist" que tem como objetivo incluir a performance sexual: ironia, política e feminismo, pois, essa configuração subverteria a passividade da mulher, apresentando-a como uma sexualidade forte e agressiva. De acordo com Nancy Prada (2012), o movimento feminista pornô ou pós-pornô traz como ideal o rompimento com a pornografia mainstream e promove a aceitação dos prazeres pelo público feminino, colocando como uma possível ferramenta para emancipação das mulheres.

O movimento em questão seria a tentativa de diversos agentes, sobretudo, mulheres para se inserir no campo de forma 'herética', ou seja, contestando como 'pretendestes' o que foi estabelecido durante séculos pelos 'dominantes'. Deste modo, Preciado (2011) acrescenta que o movimento possibilita que o corpo seja pensado como se fosse composto por próteses para se desvincular cada vez mais das próteses naturalizadas, que perduraram como "verdades" únicas e absolutas, durante séculos. Essas próteses como a vagina, o peito e o pênis são "tecnologias de gênero", construídas socialmente. Tal concepção provoca uma possibilidade mais abrangente e múltipla de subjetividades, identificando diferentes possibilidades de prazeres, remetendo um resgate de uma estética da existência como se refere Denilson Lopes ao citar Foucault:

[...] aproxima-se mais do desejo do resgate de Foucault de uma estética da existência que associa ética e estética à medida que "o estilo é autoformação ou criação equivalente ao que chamamos uma obra de arte" [...], na busca não tanto de uma "identidade gay, lésbica ou queer mas de identificações momentâneas ou duráveis" [...], apontando para a morte do homem, da mulher [...] mas também da homossexualidade [...]. $\mathrm{O}$ andrógino, para Echavarren, é um mutante marcado pelo devir do estilo [...], abre uma outra possibilidade distinta e provocadora [...] (LOPES, 2016, p. 7).

Tal lógica vai ao encontro do pensamento da associação Orbita Diversa"I, uma das militantes do feminismo pornô, que destaca que o movimento tem como principal pressuposto não evidenciar um único espectador do sexo feminino, mas reconhece a variedade de espectadorxs ${ }^{\prime V}$ com vários gostos e preferências, questionando através das imagens as representações dominantes de "gênero, orientação sexual, raça, etnia, posição social e outros elementos determinantes da identidade de cada um", "com objetivo de derrubar a desigualdade, papéis de gênero, heteronormatividade e homonormatividade"; promovendo diferentes possibilidades de "expressão de identidade" e "partilha de poderes" (BOLLOSAPIENS, 2013, tradução livre).

Esses 'pretendentes' do campo da sexualidade pontuados aqui não pretendem transformar o campo da sexuali- 
dade como algo independente, mas sim utilizá-lo como ferramenta política, social e econômica para discutir e modificar as normas, regras e moralidades sociais, ou seja, utilizar do microcosmo, fazendo uso da categoria pornografia para afetar os macrocosmos.

Tal formulação de pensamento ganhou força devido a teorias pós-coloniais e teorias queer, que servem para pensar o movimento, segundo Beatriz Preciado (2011) em seu texto "Multidões Queer", pois são um grito na porta dos movimentos sociais anteriores, dizendo que agora somos muitos, somos multidões, somos uma multidão sem rosto. De uma multiplicidade infinita com identidades transculturais e transitórias:

O locus da construção da subjetividade política parece ter se deslocado das tradicionais categorias de classe, trabalho e divisão sexual do trabalho a outras constelações transversais como podem ser o corpo, a sexualidade, a raça; mas também a nacionalidade, a língua, o estilo ou, inclusive, a imagem. (PRECIADO apud CARRILLO, 2010, p. 54).

Logo, ao se fazer referência aos modelos de controle de Foucault (2008), que também pode-se entendido pela ótica dos macrocosmos de Bourdieu, pode-se observar o feminismo pornô como resistência ao "discurso disciplinar da construção dos corpos gênero e desejos", que segundo o autor vem se multiplicando há três séculos (FOUCAULT, 2008 , p. 55); proporcionando um distanciamento a ideia de uma pornografia ligada à origem epistemológica de seu termo, além de desvincular cada vez mais a hipótese atribuída pelo senso comum de que pornografia se limita ao público masculino, o que contrasta com a pesquisa realizada pelo site Homegrouwn Vídeo, em 2013, que verificou que 56,9\% dos vídeos amadores são postados por usuários mulheres ${ }^{\vee}$. Reforçando assim, a tentativa de luta no campo da sexualidade, cujos novos pretendentes de forma "herética" tentam se inserir e modificar as regras, pois a sociedade está demandando cada vez mais diferentes possibilidades de fala e produção para a categoria pornografia como forma, sobretudo, de emancipação feminina.

\section{A pornografia mainstream e a Indústria Cultural}

Como foi visto o campo da sexualidade se trata de um campo 'heterônomo' e a construção da categoria pornografia pode ser entendida como forma de 'refração', porém ainda baseada nos pressupostos mais amplos sociais. Sendo assim, a categoria por ter sido pensada originalmente para um público masculino se relaciona as formas como os macrocosmos posicionavam as relações de divisão dos sexos, principalmente, a forma que o campo da biomedicina-social moldou o entendimento do prazer sexual.

Thomas Laqueur (2001) descreve em sua obra 'Inventando o Sexo', a aventura de um médico do século XVIII que possui obsessão em distinguir morte real de morte aparente. A história conta que ele se depara com uma jovem aristocrata considerada muito bonita que foi dada como morta, sua família pediu para que um monge a velasse durante a noite, já que seu enterro ocorreria somente no dia seguinte. $O$ monge admirado por tamanha beleza e indignado com o corpo que apresentava feições bastante vivas deixou de lado seus votos e tomou liberdade com a morta que somente o matrimônio teria permitido; envergonhado com o acontecido o monge partiu na manhã seguinte sem aguardar o sepultamento. Na hora do enterro quando a tumba estava sendo abaixada sentiram 
movimentos no interior do caixão e descobriram que a moça ainda estava viva e se tratava por tanto de uma morte aparente. Tempo depois a moça descobriu que estava grávida.

Tal história fez com que o famoso cirurgião Antoine Louis chegasse à conclusão que o orgasmo feminino era irrelevante para a concepção, em 1752, modificando todo o pensamento até então sobre a concepção que antes previa "quando a semente frutifica no ato da geração (do homem e da mulher) dá-se ao mesmo tempo uma extraordinária excitação e deleite em todos os membros do corpo". Transformando toda uma esfera de pensamentos, e colocando essa recém "descoberta" como verdade, o que abriu a "possibilidade da passividade e falta de paixão da mulher". A psicologia-contemporânea, que apontava que "o homem deseja o sexo e a mulher deseja relacionamentos" é a inversão das noções do pré-iluminismo que, desde a Antiguidade, ligava a amizade aos homens e a sensualidade às mulheres (LAQUEUR, 2001, p. 15).

As mulheres, cujos desejos não conheciam fronteiras no antigo esquema e cuja razão oferecia pouca resistência à paixão, tornaram-se, em alguns relatos, criaturas com uma vida reprodutiva anestesiada dos prazeres carnais. Quando, no final do século XVIII, passou-se a pensar que "a maioria das mulheres não se preocupava com sentimentos sexuais", a presença ou ausência do orgasmo tornou-se um marco biológico da diferença sexual (LAQUEUR, 2001, p. 15-16).

Unido a essa ideia veio à construção das diferenças dos sexos masculino e feminino, entre o homem e a mulher, em distinções biológicas, mas também distinções em todo aspecto concebível "do corpo e da alma, em todo aspecto fí- sico e moral", "uma série de oposições e contrastes", também transformando o pensamento que prevaleceu durante séculos, cujo os escritos de Aristóteles e Herófilo deram forças para o entendimento da existência de único sexo, sendo a "vagina como um pênis interno, os lábios como prepúcio, o útero como o escroto e os ovários como os testículos", mantendo somente a visão de que o corpo da mulher, faltava o que os filósofos chamavam de "falta de calor vital - de perfeição", pois somente o homem tinham as estruturas visíveis na parte externa (LAQUEUR, 2001, p. 16-17).

No século XIX tais diferenças foram amplificadas para distinções a níveis microscópicos, no qual a psicanálise reforçava a biologia e a medicina configurando o corpo feminino como algo mais "passivo, conservador, indolente e variável" (LAQUEUR, 2001, p. 18). O que reforçava e legitimava a justificativa dos respectivos papéis culturais do homem e da mulher. Esse processo de diferenciação anatômica e fisiológica, entre o homem e a mulher, surge, segundo o autor, pois essas diferenças se tornaram politicamente importante. "A política, amplamente compreendida como competição de poder, criou novas formas de constituir o sujeito e as realidades sociais dentro das quais o homem vivia" (LAQUEUR, 2001, p. 18).

Falar sobre sexualidade é falar sobre a ordem social que ela representava e a legitimava. Para as feministas, como Catharine Mackinnon, a divisão de gênero entre homens e mulheres é causado pelas exigências sociais de heterossexualidade, que institucionalizam a dominação sexual masculina e a submissão feminina, o sexo são relações sociais que servem para a mesma coisa, ou seja, é organizada para que o homem possa dominar e a mulher submeter-se a ele. 
Apesar das diferenças epistêmicas, o corpo masculino sempre foi dado como um padrão, onde somente o corpo feminino é mutável de entendimento, cuja sócio-biologia construiu uma considerável e frequente tendência misógina em grande parte das pesquisas sobre as mulheres, e a história trabalhou claramente para racionalizar e legitimar as distinções, não só de sexo mas também de raça e classe, com desvantagem para os destituídos de poder. Desta forma, não é possível escrever a história do corpo do homem e seus prazeres porque o registro histórico foi criado em uma tradição cultural onde essa história não é necessária. Mas, a construção da distinção de dois sexos se baseia claramente no processo de heteronormatividade, o que reforça os papéis sociais de ambos os sexos, sobretudo, em relação à sexualidade e o prazer.

O discurso dos conteúdos pornográficos midiatizados reforçava esses entendimentos de distinção dos sexos e seus papéis sociais, apontando a figura feminina no sentido de subserviência do prazer masculino que se tornara o ápice da temática. O gozo masculino evidenciado na narrativa como potência, poder e desfecho da trama. Já o orgasmo feminino, muito pouco evidenciado e quando apresentado em sua maioria das vezes de forma falseada, era modelado de forma fetichizada que promovesse a virilidade do homem. Os roteiros na verdade reproduziam as convencionalidades dos saberes e valores inscritos.

Não à toa esse conteúdo se expandiu em meados do século $X X$, onde o pós-guerra faz com que as experiências tornam-se mais individualizadas, as tecnologias de imagem tomam proporções maiores e se instaura um consumo de cultura de massa devido à 'democratização' de um tempo livre, que antes era privilégio das classes dominantes, que atribui um tempo muito específico não só para o repouso, mas um tempo para o consumo. A pornografia se instala como dispositivo virtual (literário, audiovisual, cibernético), como representação pública, e ao se tornar "pública" implica direta ou indiretamente comercializável "aderindo todas as características da indústria cultural: virtuosidade, possibilidade de reprodução técnica [...]" (PRECIADO, 2008, p. 170-171, tradução livre).

A Indústria Cultural, termo cunhado por Theodor Adorno e Max Horkheimer, designa a situação da arte na sociedade capitalista industrial, que transforma a cultura em produto a ser consumido e por consequência apaga e neutraliza a arte erudita e arte popular, esvaziando os valores críticos e neutralizando a participação cultural, pois desencoraja o esforço pessoal de questionamento do mundo pela posse de uma experiência estética e espetacularizada, fazendo com que o público se torne uma massa homogênea, que procure apenas o conhecido, o experimentado. A pornografia mainstream reforça não somente as ideias que normatizam o mundo moderno, seja pela relação de poder e por pura estética, como também pelo fato que independente do seu modelo de disseminação, seja ele: audiovisual, fonográfico, fotográfico ou performático, surge para tornar a experiência sexual em algo rentável e consumido como um produto de lazer que tem a excitação como único fim em si mesma.

A pornografia na sua inserção vendável pela Indústria Cultural transforma a sexualidade, o sexo, o prazer, o gozo em formas discursivas, espectacularizadas e consumíveis, de forma homogeneizadora que atendam os interesses hegemônicos da construção da masculinidade e da feminilidade, a fim de manter de forma sistêmica um processo de dominação e controle. 
Esses discursos historicizados que fazem compreender o processo e a construção social seriam os vencedores, os legitimados. Ou seja, aqueles que são construídos de forma dinâmica, como campo de luta do significar social, atrelada a correlação de forças dadas pelos agentes sociais no contexto em que vivem.

Porém, como propõe Raymond Williams (2011) esses processos estão em constante transformação e por mais hegemônico que seja determinada visão de mundo, cabe aqui destacar a misógina e o machismo, nunca consegue abarcar sua totalidade. As brechas permanecem advindas de elementos "residuais" de posições anteriormente hegemônicas ou pelo menos posições que não são contemplados pela visão predominantemente de parcelas sociais insatisfeitas com atual quadro de forças, que não se sentem representadas e que se propõem a fazer valer seu papel como agentes/sujeitos no jogo de forças dentro do processo de atribuição e circulação de significados sociais, destaque aqui para as diferentes correntes feministas.

Desta forma, a corrente feminista pornô se apresenta como um agente "emergente" no campo da sexualidade, que surge para questionar e propor alternativas, confrontando não somente o modelo de pornografia mainstream, mas os diversos saberes e poderes hegemônicos que prevaleceram ao longo dos séculos. Nesse campo de lutas, entre confrontos e negociação a cultura se faz e refaz, processual e dinamicamente.

\section{Pornografia Feminista e o olhar sobre o Corpo da mulher}

Lato sensu a pornografia é realizada para ser vista e o ato de ver produz efeitos sobre sujeitos e produz relações de poder na medida que por seu caráter ativo, a visão é, de todos os sentidos, talvez aquele que mais expresse a presença e eficácia do poder. Muitas das operações próprias do poder se realizam e se efetivam no olhar, por meio do olhar. É pelo olhar que o homem transforma a mulher em objeto: imobilizada e disponível para seu desfrute e consumo. (SILVA, 1999, p. 89)

Pode-se questionar, entretanto, se há uma outra forma de "ver este olhar", se o modo pelo qual este tem sido realizado é a única maneira de existência do mesmo o que redundaria em uma impossibilidade total de haver, como exemplo e por ser o mote deste artigo, uma pornografia não objetificadora da mulher.

É possível postular a mutualidade, a horizontalidade, do olhar? É possível reivindicar o poder subversivo, rebelde, do olhar desafiante, irreverente? Será inevitável ao olhar servir de mediador apenas de relações de poder e saber que objetificam, que inferiorizam o outro? Seremos obrigados, se quisermos compensar, de alguma forma, sua tendência verticalizante, a recorrer a um sentido sabida mente mais inclinado à simetria e à horizontalidade, como o ouvir e o escutar? Perguntas similares podem ser feitas a respeito da representação. Será possível separar, de alguma forma, a representação de sua cumplicidade com o poder? (SILVA, 1999, p. 62)

Afirma Foucault (1999. p. 88) que o poder não é uma "invencível unidade", é móvel, o que redundaria numa impossibilidade de pensar na pornografia como sendo única e possível do ponto de vista do poder de quem olha a partir da objetificação da mulher. Como de resto toda a expressão artística, inclusive agregada à indústria cultural, a pornografia é um campo em disputa, de multiplicidades 
de discursos que, se tem tido mais eco e volume um viés do mesmo isso não significa que o torne imune a resistências, deslocamentos.

Dentro do movimento feminista, a pornografia, desde a década de 1970, provoca acaloradas discussões visíveis até os dias atuais. De um lado a corrente das aliadas ao feminismo radical, que empregam à pornografia uma violência contra a mulher, pois a reduzem como mercadoria. De outro as feministas pró-sexo que acreditam na liberdade sexual como um dos instrumentos mais básicos para a emancipação feminina, porém esta corrente não nega que as produções deste gênero são pouco atrativas para o público feminino, e alegam que para a pornografia se tornar libertadora seria necessário produzir conteúdos com o olhar feminista.

A pornografia é, em geral, um fazer que tem por principal consumidor homens urbanos o que acaba por dar a este material uma narrativa voltada à apreciação do público a que se destina. Este estado de coisas gerou um debate em torno do assunto que, nas décadas de 70 e 80 do século XX nos EUA teve como principal "debatedoras" feministas pró sexo e feministas anti- pornografia. As primeiras salientavam que o problema estava no uso que se faz da pornografia não dela em si, as segundas consideravam ser a pornografia uma violência contra as mulheres. A anti- pornografia partia do seguinte pressuposto:

A sexualidade é para o feminismo o que o trabalho é para o marxismo: o que é mais próprio de cada um e o que mais se tira de cada um... A sexualidade é este processo social que cria, organiza, expressa e direciona o desejo, criando os seres sociais que conhecemos como homens e mulheres, do mesmo modo como suas relações criam a sociedade... Assim como a expropriação organizada do trabalho de alguns para o benefício de outros define uma classe - a dos trabalhadores - a expropriação organizada da sexualidade de alguns para o uso de outros define o sexo, mulher" (MACKINNON apud HARAWAY, 2004)

Passados quarenta anos do boom do mercado pornográfico, devido a maior inserção da mulher em diversos campos sociais, aliado ao surgimento das novas tecnologias e sua popularização, que proporcionaram um menor custo às produções de conteúdo informacional, na primeira década da virada do século emergiu um movimento categorizado como "feminist porn" ou "pós-porno", que possui um campo bastante amplo de propostas inclusas na categoria. Sendo assim, a discussão ganha nova importância com a popularização do gênero, reconfigurando não apenas o mercado, mas principalmente, os discursos pornográficos e suas consequentes representações. Isso pode ser atribuído à desnaturalização da relação sexualidade/reprodução, da quebra de atribuições sociais e características psicológicas atreladas aos dois sexos se fazem importantes por considerar que "repensar as relações entre os sexos [...] é repensar as relações de dominação de um sexo sobre outro e toda a estrutura de relações sociais" (LOYOLA, 1999, p.34).

A pornografia feminista tem uma gama enorme de formas de representar, justamente para fugir das práticas homogeneizante de normatização dos corpos, tendo como principal objetivo fugir do binarismo e da construção de um gozo ou uma prática legitima. Utiliza-se de diferentes formas de artes para construir novas formas de significação do mundo, confrontando os macrocosmos estabelecidos e historicamente legitimados.

De acordo com Terry Eagleton a cultura como "sinal, imagem, significado, valor, identidade, solidariedade e au- 
toexpressão" é utilizada como forma de combate político, pois segundo eles esses pontos dentro da cultura política são ligados a ideia de subjetividade. Portando, para o autor, cultura significa o domínio da subjetividade social (EAGLETON, 2011, p. 61-62).

\section{Considerações Finais}

A arte talvez seja, de forma paradoxal, a tradução mais simples e, ao mesmo tempo, refinada da singularidade do olhar (in)consciente de um tempo, de um lugar, de uma cultura. Uma observação mais atenta à obra de arte nos suscita o desafio de refletir sobre a forma com que os indivíduos e suas sociedades medeiam e representam o conflito entre seus mundos interno e externo. Por isso, "o prazer que extraímos da representação deve-se não apenas à beleza de que pode estar revestido, mas também à sua qualidade essencial de presente." (BAUDELAIRE, 2010, p. 14). Assim, não há dúvida quanto à dupla importância do papel da arte enquanto representação. De um lado, memória (individual e coletiva) da consciência subjetiva de um ser que se diferencia justamente pela forma com que exprime seus níveis de consciência, e de outro, a sua capacidade de comunicar valores.

Sendo assim, se torna evidente o motivo pelo qual o movimento feminista pornô, como "emergente" no campo da sexualidade, faz uso da arte, da cultura, como forma de luta simbólica e política para criar novas possibilidades de subjetividades mais democráticas, inclusivas e libertadoras. O movimento se aproveita da categoria por se tratar de um campo heterônomo para alcançar outros campos e de forma herética, confronta e questiona o status quo, fazendo emergir diferentes alternativas de saberes, valores e formas de pertencimento, fazendo da estética a construção de uma ética.

\section{Bibliografia}

BAUDELAIRE, Charles. As Flores do Mal. São Paulo: Martin Claret, 2010.

BENJAMIN, Walter (1984). Origem do drama barroco alemão. Trad. Rubens R. Torres Filho. São Paulo: Brasiliense.

BOLLOSAPIENS. ¿Qué es el porno feminista? (2013) In: Orbita Diversa. Disponível em: < http:// orbitadiversa.wordpress.com/2013/06/19/porno-feminista/>. Último acesso em jun. 2016.

BOURDIEU, Pierre. Algumas propriedades dos campos. In: BOURDIEU, Pierre. Questões de sociologia. Rio de Janeiro: Marco Zero, 1983. p. 89-94.

BOURDIEU, Pierre. Os usos sociais da ciência: por uma sociologia clínica do campo científico. São Paulo: UNESP, 2004.

BRAGA, Eliane Rose Maio. "Palavrões" ou palavras: um estudo com educadoras/es sobre sinônimos usados na denominação de temas relacionados ao sexo. São Paulo: UNESP, 2008.

BUTLER, Judith. Problemas de Gênero: Feminismo e subversão da Identidade. Rio de Janeiro: Civilização Brasileira, 2010.

CARRILLO, J. Entrevista com Beatriz Preciado. Revista Poiésis, n. 15, p. 47-71, jul. de 2010.

CARVALHO, Victa. Dispositivos em evidência: a imagem como experiência em ambientes imersivos In: Limiares da Imagem: tecnologia e estética na cultura contemporânea. Rio de Janeiro: Mauad Editora Ltda., 2006, p. 77-90.

CHAUÍ, Marilena. Repressão sexual: Essa nossa (des)conhecida. São Paulo: Brasiliense, 1984.

DÍAZ-BENITEZ, María Elvira. Nas redes do sexoos bastidores do pornô brasileiro. Rio de Janeiro: Zahar, 2010.

DUARTE, Jorge; BARROS, Antonio. Métodos e Técnicas de Pesquisa em Comunicação. São Paulo: Editora Atlas, 2005.

EAGLETON, Terry. Cultura em crise. In: A ideia de cultura. São Paulo: UNESP, 2011. p. 51 a 77

FLUSSER, Vilém. Natural: mente: vários acessos ao significado de natureza. São Paulo: Duas Cidades, 1979. 
FOUCAULT, Michel. A Arqueologia do Saber. Rio de Janeiro: Forense Universitária, 2008.

FOUCAULT, Michel. História da Sexualidade 1: A vontade de saber. Rio de Janeiro: Graal, 1980.

GIDDENS, Anthony. A transformação da intimidade: Sexualidade, amor, e erotismo nas sociedades modernas. São Paulo: Editora da Universidade Estadual Paulista, 1993.

HARAWAY, Donna. "Gênero" para um dicionário marxista: a política sexual de uma palavra. Cad. Pagu, Campinas, n. 22, p. 201-246, June 2004. Disponível em <http://www.scielo. br/scielo.php?script=sci_arttext \&pid=S0104$-83332004000100009 \&$ lng=en\&nrm=iso>. Acesso em 12 janeiro 2017.

HEILBORN, Maria Luiza. Construção de si, gênero e sexualidade. In: Sexualidade: o olhar das ciências sociais. Rio de Janeiro: Zahar, 1999. p.40-58.

HORKHEIMER, Max; ADORNO, Theodor. A indústria cultural: o iluminismo como mistificação de massas. In: LIMA, Luiz Costa. Teoria da cultura de massa. São Paulo: Paz e Terra, 2002. p. 169-214.

LAQUEUR, Thomas. "Da linguagem e da carne". In: Inventando o Sexo. Rio de Janeiro: Relume Dumará, 2001.

LEITE JR, Jorge. Das maravilhas e prodígios sexuais: a pornografia "bizarra" como entretenimento. São Paulo: Ed. Annablume, 2006.

LOPES, Denilson. Afetos. Estudos Queer e Artifício na América Latina. E-Compós, Brasília, v. 19, p. 1-16, 2016.

LOURO, Guacira Lopes. Pedagogias da sexualidade. In: O Corpo Educado: pedagogias da sexualidade. Belo Horizonte: Autêntica, 2001. p.9-32.

LOYOLA, Maria Andréa (org.). A Sexualidade nas Ciências Humanas. Rio de Janeiro: EdUERJ, 1998.

MORAES, Eliane Robert; LAPEIZ, Sandra. O que é pornografia. São Paulo: Brasiliense, 1984.

PRADA, Nancy. Todas las caperucitas rojas se vuelven lobos en la práctica pospornográfica. Cad. Paguno, Campinas, n. 38, jan./jun. 2012.

PRECIADO, B. Manifiesto contrasexual. Barcelona: Anagrama, 2011.
PRECIADO, B. Pornotopía: arquitectura y sexualidad en "Playboy" durante la guerra fría. Barcelona: Anagrama, 2010.

PRECIADO, B. Testo Yonqui. Madrid: Editora Espasa Calpe, 2008.

SILVA, Tomaz Tadeu da. O currículo como fetiche: a poética e a política do texto curricular. Belo Horizonte: Autêntica, 1999.

WEEKS, Jefrey. O corpo e a sexualidade. In: LOURO, Guacira Lopes. O Corpo Educado: pedagogias da sexualidade. Belo Horizonte: Autêntica, 2001. p. 34-82.

WILLIAMS, Linda. Hard Core: power, pleasure and frenzy of the visible. California: University of California Press, 1986.

WILLIAMS, Raymond. Cultura e materialismo. São Paulo: Editora Unesp, 2011.

\section{Recebido em 20/08/2018 Aprovado em 27/08/2018}

\footnotetext{
I Flávia Lages de Castro. Brasil. Doutora em Sociologia e Direito. Professora do Programa de Pós Graduação em Cultura e Territorialidades - Universidade Federal Fluminense. Contato: flavialages@id.uff.br

II Juliana Crespo. Brasil. Mestranda do Curso de Cultura e Territorialidades da UFF, Contato: juliana247@msn. com
}

III Coletivo formado por 50 pessoas com diferentes graduações, formando um grupo multidisciplinar internacional, que coordena ações, militâncias e artigos sobre a temática feminista. Outras informações em https://orbitadiversa.wordpress.com/nosotrxs/ . Última visualização agosto de 2018 .

IV Atualmente faz-se uso do " $x$ ", principalmente nos meios tecnológicos para desconstruir os binarismos de gênero.

V Informações disponíveis em: <http://www.pop.com. $\mathrm{br} / \mathrm{mundopop} / \mathrm{mulher}$-ht/-Sabe-quem-mais-filma-e-faz-upload-de-porno-caseiro-nos-EUA--1053106.html>. Último acesso em junho de 2016 